\title{
A COMPARATIVE STUDY OF THE ANTI-OXIDATIVE AND ANTI-DIABETIC POTENTIAL OF IN VITRO AND IN VIVO ROOT AND LEAF EXTRACTS OF WITHANIA SOMNIFERA ON STREPTOZOTOCIN INDUCED DIABETIC RATS
}

\author{
SOMANATHA JENA ${ }^{1,2^{*}}$, RAM C. JENA ${ }^{1 *}+{ }^{*}$, RASMITA BHOL $^{2}$, KHUSBU AGARWAL ${ }^{1}$, ANSUMAN SARANGI ${ }^{4}$, PRAMOD K. \\ SAHU ${ }^{2,3}$, SWARNA L. MISHRA ${ }^{2,3}$
}

${ }^{1}$ Post Graduate Department of Botany, Utkal University, Bhubaneswar 751004, Odisha, India, ${ }^{2}$ Department of Biotechnology, Rama Devi Women's University, Bhubaneswar, Odisha, India, ${ }^{3}$ Department of Zoology, Rama Devi Women's University, Bhubaneswar, Odisha, India, ${ }^{4}$ Trident Academy of Creative Technology, Bhubaneswar, Odisha, India

†Email: jena_ramchandra@yahoo.co.in

Received: 22 Jul 2015 Revised and Accepted: 12 Aug 2016

\section{ABSTRACT}

Objective: The present investigation explores the possibilities of using the in vitro and in vivo root and leaf extracts of Withania somnifera for antidiabetic and anti-hyperlipidaemic effects on streptozotocin-induced diabetic rats.

Methods: In vitro shoot cultures of Withania somnifera were raised by the axillary proliferation in nodal explants from a garden grown plant using Murashige and Skoog medium then in vitro raised roots and shoots were used for the anti-hyperglycemic and anti-hyperlipidaemic experiment After $72 \mathrm{~h}$ of STZ administration, the fasting blood glucose levels were measured and the rats showing FBG level $>220 \mathrm{mg} / \mathrm{dl}$ were considered to be diabetic and were used for the hyperglycemic study. In vitro and in vivo methanolic root and leaf extracts were orally administered daily to diabetic rats for eight weeks. After the treatment period, blood glucose and serum enzymes like aspartate transaminase (AST), alanine transaminase (ALT), alkaline phosphatase (ALP), total cholesterol, triglycerides, HDL-c high density lipoprotein-bound cholesterol, LDL-c low density lipoprotein-bound cholesterol, LDH, serum protein level, total phenolics and anti-oxidative analysis (DPPH and FRAP) were determined.

Results: The levels of blood glucose, AST, ALT, ALP, LDH, HDL-c significantly increased by the use of in vitro methanolic root extracts compared to normal control rats. However, remarkable loss of total protein, albumin, albumin: globulin (A: G) ratio was reported in streptozotocin-induced diabetic rats by using in vitro root extracts. Methanolic in vitro root extract at the dose levels of $300 \mathrm{mg} / \mathrm{kg}$ body weight produced a significant decrease in fasting blood glucose (FBG) level by 102.65 with respect to initial fasting blood glucose level after $30 \mathrm{~d}$ of the treatment. In vitro root extract demonstrated highest DPPH and FRAP free radical scavenging activity, i.e. $86.55 \pm 1.77$ and $48.87 \pm 2.55$ than other extracts.

Conclusion: It may be concluded that methanolic in vitro root extract $W$. somnifera at the dose $(300 \mathrm{mg} / \mathrm{kg})$ has more potent anti-hyperglycaemic activity than the other in vitro and in vivo extracts of leaf and root on streptozotocin induced diabetic rats and was also found to be similar in effect to that of the standard drug 'Glibenclamide'.

Keywords: Withania somnifera, Anti-diabetic, Anti-hyperlipidaemic, Diabetes mellitus, Streptozotocin, Anti-oxidant, DPPH, FRAP

(c) 2016 The Authors. Published by Innovare Academic Sciences Pvt Ltd. This is an open access article under the CC BY license (http://creativecommons. org/licenses/by/4. 0/) DOI: http://dx.doi.org/10.22159/ijpps.2016v8i10.8103

\section{INTRODUCTION}

Withania somnifera Dunal (Solanaceae), known as Ashwagandha in Sanskrit or Winter cherry in English, is one of the most valued plants of the traditional Indian system of medicine. The plant is used in more than 100 formulations of Ayurveda, Unani and Siddha and is therapeutically equivalent of ginseng [1]; hence is called popularly as 'Indian ginseng.' Plants have been the major source of drugs for the treatment of diabetes mellitus (DM) in Indian medicine and other ancient systems in the world, and for a long time DM has been treated orally with herbal medicines or their extracts because plant products are frequently considered to be less toxic and is comparatively free from side effects than synthetic ones $[2,3]$. Furthermore, after the recommendations made by the WHO on DM, investigations on hypoglycemic agents from medicinal plants have become more important and the search for more effective and safer hypoglycemic agents have continued to be an important area of active research. World Ethno-botanical information on medicinal plants reported that almost 800 plants can be used to control DM Many herbs and plants have been described as possessing hypoglycemic activity when taken orally $[2,3]$. Some of these plants have also been pharmacologically tested and have shown to be of immense value in human diabetes treatment. The pharmacological effect of the roots of $W$. somnifera is attributed to the presence of withanolides, a group of steroidal lactones [4]. Its leaves are used in Ayurvedic and Unani systems for treatment of tumors and tubercular glands [5]. A number of withanolide steroidal lactones have been isolated from the leaves of $W$. somnifera [6] and its positive effect on anti-bacterial, anti-fungal and anti-tumor properties reported by Glotter et al. 1973 [7] There are a number of reports elucidating the chemical and pharmacological properties of W. somnifera [8-10].

W. somnifera is a shrubby plant cultivated in India, parts of East Asia and Africa which offers tremendous potential as an energizing medicinal herb. Ayurvedic practitioners have used the roots of this plant for centuries with success as a tonic to increase vitality and longevity, as well as to treat health conditions as diverse as tumors and arthritis. Recent laboratory studies have begun to confirm what Ayurvedic practitioners have known for years that $W$. somnifera deserves attention as an herbal therapy to ease or even eliminate many of today's common health problems. Hypoglycemic activity of 'Trasina' (an ayurvedic formulation) containing extract of $W$. somnifera as one of the important constituents has been established beyond doubt and this activity may be due to its antioxidant properties [11]. It is being in use for a pretty long time for all age groups and for both sexes and even during pregnancy without any side effects. The traditional uses and anti-diabetic activity of $W$. somnifera have been reviewed [12]. Hypoglycemic effects [13] and the effects of $W$. somnifera on insulin sensitivity in NIDDM rats [14] have been reported. The chemistry and nutritional properties of phenolic compounds, including flavonoids, have been extensively 
reviewed [15]. Flavonoids are commonly found in all plants and also possess hypoglycemic and antidiabetic activities [16]. Therefore, the present study is aimed at determining the anti-oxidant, anti-diabetic and anti-hyperlipidaemic effects of in vivo and in vitro $W$. somnifera root (WSREt) and leaf (WSLEt) extracts on streptozotocin-induced DM rats.

\section{MATERIALS AND METHODS}

\section{Plant material}

Seeds of $W$. somnifera were procured from the Central Institute of Medicinal and Aromatic Plants (CIMAP), Lucknow, India and the plants were grown in the experimental garden in Rama Devi Women's University, Bhubaneswar, Odisha, India. The plants were collected in the month of August 2013, and the plant parts like root and leaf were selected for the anti-diabetic activity. In vitro shoot cultures of $W$. somnifera were raised by auxiliary proliferation in nodal explants from a garden grown plant using Murashige and Skoog [17] medium and the in vitro raised roots and shoots were used for the anti-hyperglycemic and anti-hyperlipidaemic experiment.

\section{Preparation of plant extracts}

Freshly collected in vitro and in vivo plant parts (leaf and root) was washed under running tap water, dried under shade and powdered with the help of mechanical grinder. The course powder was first digested with petroleum ether $\left(40-60{ }^{\circ} \mathrm{C}\right)$ followed by extraction with methanol in Soxhlet apparatus for $48 \mathrm{~h}$. The leaf and root extracts were filtered separately and concentrated under vacuum. The yield of the extracts from root and leaf was about 76 and $72 \mathrm{~g}$, respectively with respect to the dried powder plant material. The methanolic and aqueous extracts were then separately suspended in Tween-80 (5\% v/v) and screened for anti-hyperglycemic and antihyper-lipidaemic activity.

\section{Animals}

The experiments were carried out on thirty-six male healthy adult albino wistar strain rats (150-180 g bw) procured from an authorized firm in Bhubaneswar. They were housed in plastic cages with filter tops under controlled conditions of $12 \mathrm{~h}$ light/12 $\mathrm{h}$ dark cycle, $50 \%$ humidity and $28 \pm 2{ }^{\circ} \mathrm{C}$. They all received a standard pellet diet and water. The standard pellet diet contained $21 \%$ crude protein, $5 \%$ fat, $4 \%$ crude fiber, $8 \%$ ash, $1 \%$ calcium, $0.6 \%$ phosphorus, $2 \%$ vitamins and $55 \%$ nitrogen free extract (carbohydrates). The animals were maintained in the department of pharmaceutical sciences as per the principles and guidelines of the ethical committee for animal care of Utkal University (Odisha, India) in accordance with the Indian National Law on AnimalCare and Use (CPCSEA).

\section{Experimental design and treatment}

The rats were injected with streptozotocin dissolved in sterile normal saline at a dose of $60 \mathrm{mg} / \mathrm{kg}$ bw, intra-peritoneally. The rats were then kept for the next $24 \mathrm{~h}$ on $5 \%$ glucose solution bottles in their cages to prevent hypoglycaemia [18]. After a fortnight, rats with moderate diabetes having glycosauria (indicated by Benedict's test for urine) and hyperglycaemia with blood glucose range of 250$300 \mathrm{mg} / \mathrm{dl}$ were used for the experiment. Blood was collected from the eyes (venous pool) by a sino-ocular puncture for the estimation of the blood glucose.

In the experiment, a total number of 36 rats 30 diabetic-induced rats and six normal rats) were used. Diabetes was induced in rats two weeks before starting the treatment. The rats were divided into six groups in the following manner after the induction of streptozotocin diabetes and each group comprised of six rats.

Group 1: Normally controlled rats received only saline water during the experimental period. Group 2: Diabetic controlled-freshly prepared streptozotocin in saline was administered in a single dose of $60 \mathrm{mg} / \mathrm{kg}$ body weight through intraperitoneally to overnight fasted rats and the animals were allowed to develop diabetes for two weeks. Group 3: Diabetic rats were daily treated with methanolic WSREt with a dose of $200 \mathrm{mg} / \mathrm{kg}$ body weight for eight weeks. Group 4: Diabetic rats were daily treated with methanolic in vitro
WSREt with a dose of $200 \mathrm{mg} / \mathrm{kg}$ body weight for eight weeks. Group 5:Diabetic rats were daily treated with methanolic WSLEt with a dose of $200 \mathrm{mg} / \mathrm{kg}$ body weight for eight weeks. Group 6:Diabetic rats were daily treated with methanolic in vitro WSLEt with a dose of $200 \mathrm{mg} / \mathrm{kg}$ body weight for eight weeks.

\section{Collection of samples}

The rats were carefully monitored every day. The blood sugar level of all the rats was determined. After eight weeks of treatment, the rats were sacrificed by cervical dislocation. Blood was collected and processed for the biochemical estimations.

\section{Estimation of blood glucose}

In vitro and in vivo plant parts (leaf and root extracts or glibenclamide were administered orally between 12:00-02:00 P. M. on a daily basis for a period of 0-56 d. The blood samples were collected from each treated group by puncturing the tail veins, and FBG levels were measured at $57 \mathrm{~d}$. Glucose is oxidized by the enzyme glucose oxidase (GOD) to give D-gluconic acid and hydrogen peroxide. Hydrogen peroxide in the presence of enzyme peroxidase (POD) oxidizes phenol which combines with 4-amino-antipyrine to produce a red colored quinoneimine dye. The intensity of the color developed is proportional to glucose concentration in the sample. The blood samples were collected on the $56^{\text {th }}$ day (9:00-11:00 A. M) by cardiac puncture of the rats and serum were separated by centrifugation for the biochemical estimations of serum Total Cholesterol, Triglycerides, HDL cholesterol, LDL cholesterol AST: Aspartate transaminase, Alanine transaminase, Alkaline phosphatase, Lactate dehydrogenase, Albumin: Globulin.

\section{Estimation of total cholesterol by enzymatic method}

Cholesterol esterase (CHE) hydrolyzes cholesterol ester. Free cholesterol is oxidized by the cholesterol oxidase ( $\mathrm{CHO}$ ) to cholest-4-en-3-one and hydrogen peroxide. Hydrogen peroxide formed reacts with 4-aminoantipyrine and phenol in the presence of peroxidase (POD) to produce pink colored quinonimine dye. The intensity of color produced is proportional to the cholesterol concentration.

\section{Estimation of triglyceride}

Triglyceride in the sample is hydrolyzed by microbial lipases to glycerol and free fatty acids (FFA). Glycerol is phosphorylated by adenosine-5-triphosphate (ATP) to glycerol-3-phosphate (G-3-P) in the reaction catalyzed by glycerol kinase (GK). G-3-P is oxidized to dihydroxyacetone phosphate (DAP) in a reaction catalyzed by the enzyme glycerol phosphate oxidase (GPO).

In this reaction, hydrogen peroxide is produced in equimolar concentration to the level of triglycerides present in the sample. Hydrogen peroxide reacts with 4-aminoantipyrine and 3,5-Dichloro2-hydroxybenzene sulfonic acid (DHBS) in a reaction catalyzed by peroxidase. The result of this oxidative coupling is quinone imine red colored dye. The absorbance of this dye in solution is proportional to the concentration of triglycerides in the sample.

\section{Estimation of HDL cholesterol by PEG/CHOD-PAP}

The VLDL and LDL fractions of serum sample are precipitated using PTA and then HDL in the supernatant is separated by centrifugation and measured for its cholesterol content. The enzyme cholesterol ester hydrolase (CHE) hydrolyzes the ester cholesterol. Then cholesterol is oxidized by cholesterol oxidase ( $\mathrm{CHO}$ ) to cholest-4-en3-one and hydrogen peroxide. Hydrogen peroxide in the presence of enzyme peroxidase (POD) reacts with 4-aminoantipyrine and phenol to produce a red colored complex whose absorbance is proportional to HDL cholesterol concentration.

\section{Estimation of LDL cholesterol by direct enzymatic method}

Direct determination of serum LDLc (low-density lipoprotein cholesterol) levels without the need for any pretreatment or centrifugation steps. The assay takes place in two steps. In the $1^{\text {st }}$ step elimination of lipoprotein non-LDL Cholesterol and $2^{\text {nd }}$ step is the measurement of LDL. The intensity of the color formed is proportional to the LDL concentration in the sample. 
Estimation of aspartate aminotransferase (SGOT) by modified IFCC method

SGOT (AST) catalyzes the transfer of amino group between Laspartate and $\alpha$-ketoglutarate to form oxaloacetate and glutamate. The oxaloacetate formed reacts with $\mathrm{NADH}$ in the presence of malate dehydrogenase to form NAD. The rate of oxidation of NADH to NAD is measured as a decrease in absorbance which is proportional to the SGOT (AST) activity in the sample.

\section{Estimation of alanine aminotransferase (SGPT) by modified IFCC method}

SGPT (ALT) catalyzes the transfer of amino group between L-alanine and $\alpha$-ketoglutarate to form pyruvate and glutamate. The pyruvate formed reacts with NADH in the presence of lactate dehydrogenase to form NAD. The rate of oxidation of NADH to NAD is measured as a decrease in absorbance which is proportional the SGPT (ALT) activity in the sample.

\section{Estimation of lactate dehydrogenase by UV kinetic IFCC method}

Lactate dehydrogenase (LDH) catalyzes the conversion of pyruvate to lactate and NADH to NAD. LDH activity in serum is directly proportional to the rate of decrease in the absorbance of NADH at $340 \mathrm{~nm}$. Assay temperature for the estimation was $37^{\circ} \mathrm{C}$.

\section{Estimation of alkaline phosphatase (ALP) by PNPP method in serum}

The determination of the activity of alkaline phosphatase in serum based on the hydrolysis of p-nitrophenyl phosphate (PNPP) by the enzyme with the formation of free p-nitrophenol. This compound is yellow in alkaline solution. The formation of yellow color can be spectrophotometrically read at $405 \mathrm{~nm}$, which is directly proportional to the enzymatic activity of alkaline phosphatase in serum/plasma.

\section{Estimation of total protein, albumin and globulin by biuret and BCG dye binding method}

Proteins bind with copper ions in an alkaline medium of the biuret reagent and produce a purple colored complex whose absorbance is proportional to the protein concentration. Albumin in a buffered medium binds with bromocresol green (BCG) and produces a green color, whose absorbance is proportional to the albumin concentration.

\section{DPPH radical scavenging assay}

The free radical scavenging activity of in vivo and in vitro leaf and root extracts were measured using the 2, 2-diphenyl-1-picrylhydrazyl (DPPH) methods $(19,20)$ One millilitre of in vivo and in vitro leaf and root crude extracts at concentration $(200 \mu \mathrm{g} / \mathrm{ml})$ was mixed with $5 \mathrm{ml}$ of $0.004 \%(\mathrm{v} / \mathrm{v})$ DPPH and finally extracts were dissolved in methanol. The above procedures were repeated with BHT using ascorbic acid and $\alpha$-tocopherol as positive controls. The above procedures were repeated with BHT using ascorbic acid and $\alpha$-tocopherol as positive controls and the absorbance of the samples were measured at $517 \mathrm{~nm}$. Experiments were carried out in triplicate. The DPPH radical scavenging assay was calculated according to the formula.

$$
\text { Scavenging activity }(\%)=\left(\mathrm{A}_{0}-\mathrm{A}_{1}\right) / \mathrm{A}_{0} \times 100
$$

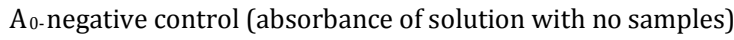

A $_{1}$-positive control (absorbance of solution with samples)

\section{Ferric reducing anti-oxidant power assay}

The ferric reducing properties of in vivo and in vitro leaf and root extracts were determined using assay described by Yen and Chen [21]. One milliliter of leaf and root methanolic extract was mixed with $2.5 \mathrm{ml}$ of potassium phosphate buffer $(0.2 \mathrm{M}, \mathrm{pH} 6.6)$ and $1 \mathrm{~g} / 100 \mathrm{ml}$ potassium ferricyanide. The mixture was incubated at $500{ }^{\circ} \mathrm{C}$ for $20 \mathrm{~min}$ followed by trichloroacetic acid $(10 \%)$ addition to stop the reaction and finally equal volume of distilled water followed by $0.5 \mathrm{ml}$ ferric chlorate $(0.1 \mathrm{~g} / 100 \mathrm{ml})\left(\mathrm{FeCl}_{3}\right)$ was added and incubated at room temperature for $30 \mathrm{~min}$, absorbance was measured at $700 \mathrm{~nm}$. The whole experiment was carried out in triplicate. The above procedures were repeated with BHT using ascorbic acid and tocopherol as positive controls. The percentage of antioxidative activity in the FRAP assay of the leaf and root extracts was calculated according to the formula.

$$
\text { Anti-oxidant activity }(\%)=\left(\mathrm{A}_{1}-\mathrm{A}_{0}\right) / \mathrm{A}_{1} \times 100
$$

$\mathrm{A}_{0}$-negative control (Absorbance of the control reaction)

$A_{1}$ positive control (Absorbance in the sample)

\section{Statistical analysis}

All the results were expressed as mean \pm SD. The results were analyzed for statistical significance by one-way analysis of variance (ANOVA) and Dunnet's multiple range test (Different alphabets were considered to be significant, $p<0.05$ ).

\section{RESULTS AND DISCUSSION}

Anti-diabetic property of normal plant extracts owes to their ability of correcting dysfunction of pancreatic $\beta$-cells restoring insulin output, hindering the intestinal absorption of glucose or to the facilitation of metabolites in insulin-dependent processes. Though numerous anti-diabetic plant genotypes have been identified, the journey for new plant genotypes, especially their key bioactive phyto-compounds would certainly be rewarding. Streptozotocininduced diabetes in rodent's results in the development of nephropathy similar to early stage clinical diabetic nephropathy [22, 23]. The present experiment was conducted to study the anti-diabetic activity of $W$. somnifera in rats to provide scientific evidence for its traditional usage in control of diabetes. Although methanolic in vitro and in vivo leaf and root extracts of $W$. somnifera revealed more or less recovery of loss body weight, but remarkable loss, body weight retrieval was demonstrated by aqueous in vitro root extracts, possibly due to strong glycemic control offered by the treatment. Strategically, the oral glucose tolerance test (OGTT) was more sensitive than fasting blood glucose (FBG) measure in being able to evaluate the effect of in vitro and in vivo leaf and root extracts in securing glycemic control, thereby leading to a reversal of normal glucose homeostasis in experimental diabetes rats.

A remarkable decrease in blood glucose was observed in diabetic controls and this study demonstrated that the in vitro root extracts protects the diabetic rats from the massive decrease in blood glucose, when given orally, daily for thirty days. Streptozotocin treated diabetic rats demonstrated a significant recovery in final blood glucose, which was close to that of normal control rats. The rise in blood glucose was far less in the poorly controlled diabetic rats as compared to well-controlled diabetic rats. This is in agreement with earlier studies on diabetic rats [24].

Free radical scavengers are chemicals that interact with and neutralize free radicals, thus preventing them from causing cellular damage in the biological system [25]. DPPH is a dark colored crystalline powder composed of stable free radical molecules [26]. The antioxidant compounds neutralize the free radical activity of DPPH by transferring either electrons or hydrogen atoms to DPPH [27], thereby changing the color from purple to the yellow colored stable diamagnetic molecule, diphenyl picrylhydrazine. The degree of discoloration indicates the scavenging power of the extract or antioxidant in terms of hydrogen donating ability [28]. The effect of methanolic in vitro root extracts of $W$. somnifera on both DPPH scavenging assay and FRPA assay in streptozotocin-induced diabetis rats is shown in (table 1). From the result of the DPPH spectrophotometric assay, The methanolic in vitro root extract demonstrated highest DPPH free radical scavenging value (86.55) and FRAP value (48.87) than the other extracts of leaf and root in both DPPH and FRAP.

A total of four leaf and root extract were examined on normal healthy, glucose loaded and streptozotocin-induced diabetes rats. The perusal of the results of anti-diabetic screening of leaf and bark extracts in normal healthy rats is shown in (table 2). This result clearly indicates that the extracts have no effect on normoglycemic animals, but have a significant role in reducing the elevated blood 
glucose level, which implies it acts through the extrapancreatic pathways rather than stimulating insulin secretion and results in antihyperglycemic effect without affecting normal blood glucose level, which may be beneficial in case of mis-dosing.

Table 1: Total phenolic and anti-oxidant activity of methanolic in vivo and in vivo root and leaf extract of $W$. somnifera

\begin{tabular}{|c|c|c|c|c|c|c|}
\hline \multirow{3}{*}{$\begin{array}{l}\text { Concentration } \\
(\mathrm{mg} / \mathrm{ml})\end{array}$} & \multicolumn{2}{|c|}{ Total phenolic(ug/mg) } & \multicolumn{4}{|l|}{ Anti-oxidant } \\
\hline & \multirow[t]{2}{*}{ Root extract } & \multirow[t]{2}{*}{ Leaf extract } & \multicolumn{2}{|l|}{ Root extract } & \multicolumn{2}{|l|}{ Leaf extract } \\
\hline & & & DPPH & FRAP & DPPH & FRAP \\
\hline In vivo-WSLEt-200 & $5.4 \pm 1.02^{\mathrm{c}}$ & $4.9 \pm 1.65^{\mathrm{d}}$ & $59.22 \pm 2.66^{\mathrm{d}}$ & $22.87 \pm 2.87^{d}$ & $42.78 \pm 3.76^{d}$ & $34.87 \pm 2.87^{\mathrm{d}}$ \\
\hline In vitro-WSLEt-200 & $5.9 \pm 1.02^{c}$ & $5.6 \pm 0.43^{c}$ & $68.99 \pm 2.43^{c}$ & $30.98 \pm 1.87 \mathrm{c}$ & $53.99 \pm 1.78^{c}$ & $42.87 \pm 2.76^{c}$ \\
\hline In vivo-WSREt-200 & $6.8 \pm 1.01^{b}$ & $6.5 \pm 1.33^{b}$ & $77.21 \pm 1.54^{\mathrm{b}}$ & $38.98 \pm 1.43^{\mathrm{b}}$ & $62.82 \pm 1.84^{\mathrm{b}}$ & $49.87 \pm 2.65^{b}$ \\
\hline Iv vitro-WSREt-200 & $8.1 \pm 1.03^{\mathrm{a}}$ & $7.7 \pm 0.87 \mathrm{a}$ & $86.55 \pm 1.77^{a}$ & $48.87 \pm 2.55^{\mathrm{a}}$ & $71.99 \pm 2.87^{\mathrm{a}}$ & $61.87 \pm 1.78^{a}$ \\
\hline
\end{tabular}

Data pooled from a total of 3 experiments showing mean values within rows (between columns) followed by different alphabets (a, b c and d) in superscript are significantly different ( $\mathrm{P} \leq 0.05$; Duncan's New Multiple Range Test).

Table 2: Effects of W. somnifera (L.) extracts on blood glucose, serum lipid profile, serum enzymes AST, ALT, ALP and LDH,total protein, albumin, globulin and A: G ratio

\begin{tabular}{|c|c|c|c|c|c|c|}
\hline Groups & $\begin{array}{l}\text { Normal } \\
\text { control }\end{array}$ & $\begin{array}{l}\text { Diabetic } \\
\text { control }\end{array}$ & Diabetic+WSREt & Diabetic+IV-WSREt & $\begin{array}{l}\text { Diabetic+ } \\
\text { WSLEt }\end{array}$ & $\begin{array}{l}\text { Diabetic+ } \\
\text { IV-WSLEt }\end{array}$ \\
\hline Blood Glucose(mg/dl) & $94.66 \pm 1.49^{\mathrm{bc}}$ & $401 \pm 1.25^{\mathrm{a}}$ & $138.34 \pm 1.44$ & $102.65 \pm 3.55^{b}$ & $143.93 \pm 1.05^{b}$ & $118.65 \pm 3.65^{b}$ \\
\hline Total Cholesterol(mg/dl) & $88.29 \pm 4.74^{d}$ & $201.87 \pm 1.04^{b}$ & $117.86 \pm 1.75^{c}$ & $98.83 \pm 2.12^{c}$ & $138.96 \pm 1.98^{c}$ & $109.32 \pm 2.21^{\mathrm{c}}$ \\
\hline Triglyceride(mg/dl) & $73.58 \pm 3.92^{\mathrm{e}}$ & $107.08 \pm 1.32^{\mathrm{de}}$ & $90.37 \pm 1.68^{\mathrm{d}}$ & $81.76 \pm 2.43^{\mathrm{de}}$ & $105.91 \pm 1.33^{\mathrm{d}}$ & $85.88 \pm 1.87^{\text {def }}$ \\
\hline HDL Cholesterol(mg/dl) & $24.66 \pm 1.53^{\mathrm{i}}$ & $27.06 \pm 1.88^{\mathrm{fg}}$ & $25.72 \pm 1.54^{\mathrm{f}}$ & $24.65 \pm 1.76^{\mathrm{h}}$ & $25.76 \pm 1.95^{\mathrm{i}}$ & $25.61 \pm 1.65^{\mathrm{i}}$ \\
\hline LDL Cholesterol(mg/dl) & $48.25 \pm 5.23 \mathrm{~g}$ & $81.37 \pm 2.65^{\text {def }}$ & $50.34 \pm 3.97 \mathrm{e}$ & $48.43 \pm 1.32^{\mathrm{f}}$ & $55.41 \pm 4.43 \mathrm{~g}$ & $49.36 \pm 1.23 \mathrm{~g}$ \\
\hline AST(IU/l) & $95.40 \pm 2.41^{\mathrm{b}}$ & $156.89 \pm 5.57 \mathrm{c}$ & $84.60 \pm 4.09 \mathrm{e}$ & $83.11 \pm 3.65^{d}$ & $96.41 \pm 5.75^{\mathrm{ef}}$ & $86.55 \pm 2.32^{\mathrm{de}}$ \\
\hline ALT(IU/l) & $71.61 \pm 3.07$ ef & $144.49 \pm 4.45^{\mathrm{cd}}$ & $88.52 \pm 5.27^{\mathrm{d}}$ & $81.54 \pm 2.43^{\mathrm{de}}$ & $97.51 \pm 5.17 \mathrm{e}$ & $89.79 \pm 1.21^{\mathrm{d}}$ \\
\hline ALP(IU/l) & $39.01 \pm 1.82^{\mathrm{h}}$ & $52.66 \pm 2.12^{\mathrm{f}}$ & $39.39 \pm 1.58^{f}$ & $39.08 \pm 1.34 \mathrm{~g}$ & $39.35 \pm 1.22^{\mathrm{h}}$ & $39.22 \pm 0.99 \mathrm{~h}$ \\
\hline LDH(IU/l) & $197.33 \pm 6.25^{\mathrm{a}}$ & $383.6 \pm 6.94 \mathrm{ab}$ & $276.50 \pm 11.96^{\mathrm{a}}$ & $223.21 \pm 3.54^{\mathrm{a}}$ & $295.23 \pm 7.79^{a}$ & $236.32 \pm 4.32^{\mathrm{a}}$ \\
\hline Total Protein(mg/dl) & $7.84 \pm 0.9^{j}$ & $8.53 \pm 0.41^{\mathrm{gh}}$ & $7.82 \pm 0.38 \mathrm{~g}$ & $7.22 \pm 0.89^{\mathrm{i}}$ & $7.98 \pm 0.43^{j}$ & $7.78 \pm 0.76^{j}$ \\
\hline Albumin(gm/dl) & $5.08 \pm 0.73^{j \mathrm{k}}$ & $5.49 \pm 0.16^{\mathrm{ghi}}$ & $4.87 \pm 0.22^{\mathrm{g}}$ & $4.10 \pm 0.77^{\mathrm{ij}}$ & $4.96 \pm 0.45^{\mathrm{k}}$ & $4.78 \pm 0.79^{j \mathrm{k}}$ \\
\hline Globulin(gm/dl) & $2.55 \pm 0.45 \mathrm{j}^{\mathrm{klm}}$ & $2.48 \pm 0.12^{\text {ghij }}$ & $2.76 \pm 0.23 \mathrm{~g}$ & $2.09 \pm 0.61^{\mathrm{ijk}}$ & $2.98 \pm 0.32^{\mathrm{kl}}$ & $2.54 \pm 0.45^{\mathrm{kl}}$ \\
\hline A: G ratio & $2.99 \pm 0.46^{\mathrm{jkl}}$ & $1.21 \pm 0.11^{\text {ghijk }}$ & $1.76 \pm 0.24 \mathrm{~g}$ & $1.96 \pm 0.04^{\mathrm{ijkl}}$ & $1.66 \pm 0.35^{\mathrm{klm}}$ & $1.88 \pm 0.17 \mathrm{klm}$ \\
\hline
\end{tabular}

Values are expressed as mean \pm SD of six samples from each group. Both WSREt and WSLEt were treated at 200 mg/kg body weight. WSREt: W. somnifera root extract, WSLEt: W. somnifera leaf extract, TC: Total Cholesterol, TG: Triglycerides, HDL cholesterol: High Density lipoprotein-bound cholesterol, LDL cholesterol: Low-density lipoprotein-bound cholesterol, AST: Aspartate transaminase, ALT: Alanine transaminase, ALP: Alkaline phosphatase, LDH: Lactate dehydrogenase, A: G ratio = Albumin in gm\%/Globulin in gm\%.

The total phenolic content of methanolic in vitro and in vivo root and leaf extracts of $W$. somnifera are $5.9 \pm 1.02,8.1 \pm 1.03,4.9 \pm 1.65$, and $6.5 \pm 1.33$ respectively. In vitro root extracts were comparatively more effective in the Oral Glucose Tolerance Test (OGTT) than in vitro and in vivo leaf and roots. There was a significant reduction in blood glucose level observed at the dose levels of $200 \mathrm{mg} / \mathrm{kg}$ of the in vitro root extracts as compared to other glucose-loaded control, which showed impaired glucose tolerance.

The methanolic in vitro root extracts at the dose of $200 \mathrm{mg} / \mathrm{kg}$ produced a significant decrease of blood glucose level than other extracts. From the results obtained, it is clear that chronic administration of $W$. somnifera leaf and root extract to streptozotocin-induced diabetes rats demonstrated blood glucose reduction in a constant dose but exposure time-dependent manner. In streptozotocin-induced diabetic rats, among all the extracts of $W$. somnifera the metabolic in vitro root at the dose level of $300 \mathrm{mg} / \mathrm{kg}$ revealed the significant highest reduction (102.65) followed by in vitro leaf extract (118.65) in fasting blood glucose level when compared to diabetic control group at the end of $30 \mathrm{~d}$ experimental period whereas the in vivo leaf and root extract at the same dose revealed 143.93 and 138.34 reductions on the same day respectively (table 2). It indicates that the plant extracts exhibited similar effects as that of the standard drug, Glibenclamide (99.45). To determine whether there was a statistically significant difference in hypoglycemia achieved by the different time intervals chronically administered, the data were compared by using one-way analysis of variance and the individual groups were compared with a control group using Dunnet's multiple range test (DMRT). The antihyperglycemic action of the root extracts may be attributed either (i) to the potentiating of pancreatic secretion of insulin from existing $\beta$ cells of islets of Langerhans or (ii) to the extrapancreatic mechanism like increased peripheral utilization of glucose through different enzymatic pathways [29]. Since neither in vitro nor in vivo methanolic root extracts of $W$. somnifera exerted any innate hypoglycemic effect on normoglycemic animals, instead significantly reduced the elevated blood glucose level resulting from induced diabetes, it implies that it acts through the extra-pancreatic pathways rather than stimulating insulin secretion and causes an anti-hyperglycemic effect without affecting normal blood glucose level. Antidiabetic agents commonly causing toxicity in overdose include sulphonylureas (i.e. chlorpropamide, glibenclamide) and insulins. When these drugs are taken in overdose are shown to cause hypoglycemia [30]. Interestingly, in our investigation, the in vitro nor in vivo root and leaf extracts did not show any hypoglycemic activity, unlike the standard anti-diabetic drug glibenclamide. Thus, the potential medicinal shrub $W$. somnifera may possibly utiliseas a harmless and effective therapeutic drug for various diseases other than diabetes. Water is generally used in traditional settings to prepare the plant decoctions for health remedies. Many natural products including pigments, enzymes and bioactive components are soluble in water, which explains the high yield of the extract [31]. Hypoglycemic effect of $W$. somnifera was also reported by some researchers [32-34, 35]. The events like potentiation of pancreatic secretion of insulin from existing $\beta$ cells of Islets of Langerhans or to the extrapancreatic mechanism such as increased peripheral utilization of glucose through different enzymatic pathways may be attributed by the action of anti-hyperglycemic effect.

Effect of administering WSREt and WSLEt to diabetic rats on serum lipids like TC, TG, serum high-density lipoprotein-bound cholesterol (HDL-c), and low-density lipoprotein-bound cholesterol (LDL-c) are presented in table 1 . The rise in blood sugar is accompanied by the increase in TC, TG, LDL-c, and fall of HDL-c in diabetic rats. The 
levels of serum TC TG and LDL-c were significantly increased in diabetic rats when compared to those of normal control rats, while the level of serum HDL-c (70\%) was significantly decreased in diabetic rats when compared to that of normal control rats (table 1). The abnormal high concentration of serum lipids is mainly due to increase in the mobilization of free fatty acids from the peripheral fat deposits because insulin inhibits the hormone sensitive lipase production. However, administering WSREt and WSLEt to diabetic rats tends to bring the values to near normal. Thus, WSREt and WSLEt treatments exhibited hypocholesterolemic, hypotriglyceridemic and hypo phospholipidomics effects while at the same time increasing the HDL-c. Therefore, the elevated level of serum lipids in DM causes the risk of coronary heart disease. It has been well established that DM alters the normal metabolism of tissues like liver, kidney and heart. The administration of WSREt and WSLEt to diabetic rats tends to bring the values to near normal. $W$. somnifera is known to have antioxidant properties [36] and this may reduce the susceptibility of lipids to oxidation and stabilize the membrane lipids thereby reducing oxidative stress.

The LDH levels were significantly increased in diabetic rats when compared to normal control rats. LDH levels showed a significant decrease in WSREt and WSLEt treated diabetic rats. Organs rich in LDH are the liver, heart and skeletal muscles. In myocardial infarction, serum LDH level begins to rise by 8-12 h of the attack, reaches to a peak within 48-72 $\mathrm{h}$ and returns to normal after 1-2 w. Elevated serum LDH levels indicate cardiac damage and a profound risk of coronary heart disease. The levels of total protein in serum and albumin and albumin: globulin (A: G) ratio in serum was significantly decreased in diabetic rats when compared to those of normal control rats. On the other hand, no change was observed in the level of serum globulin in diabetic rats when compared to that of normal control rats. The total protein levels in serum and albumin and $A: G$ ratio in serum were significantly increased in diabetic rats treated with WSREt when compared to those of diabetic rats. Hypoalbuminemia was observed in DM, which consists with another report in that the altered $A: G$ ratio was observed in diabetic rats [37]. Distinct metabolic, renal alterations lead to a negative nitrogen balance, enhanced proteolysis and lowered protein synthesis in experimental diabetes [38]. The reversal of the changes by WSREt and WSLEt therapy may be proved that the insulin deficiency had been sufficiently corrected. Serum albumin and A: G ratio, as well as total protein never deviated from the normal range throughout the treatment period in WSREt and WSLEt, treated diabetic rats. $W$. somnifera has been reported to produce anabolic effects, enhancing the synthesis of certain modulator proteins in rat liver and increasing the body weight in humans [39]. The levels of total serum proteins were found to be markedly decreased in STZ-induced diabetic rats this study. Decreased protein content of serum in diabetic patients reported by Mahboob et al., (2005) [40] were implicated with elevated lipid peroxidation process and decreased anti-oxidant defensive system. Insulin generally has an anabolic effect on protein metabolism in that it stimulates protein synthesis and retards protein degradation [41]. Therefore, a relative deficiency of insulin, due to STZ-induced degradation of pancreatic insulin secreting $\beta$-cells, protein synthesis are perhaps decreased in all tissues. This may be responsible for the decreased level of serum proteins in diabetic rats.

An increase in the activities of SGOT, SGPT and ALP in plasma might be mainly due to the leakage of these enzymes from the liver cytosol into the blood stream which gives an indication of the hepatotoxic effect of STZ [42]. The effects of administering WSREt and WSLEt to diabetic rats on and serum enzymes AST, ALT, and ALP are given in table 2. Streptozotocin administration increased liver function biomarkers such as ALP and ALT significantly in comparison with normal control rats [43]. The activities of serum enzymes like AST, ALT and ALP were significantly increased in the diabetic rats when compared to those of normal control rats. But the activities of serum AST, ALT, and ALP were significantly decreased in diabetic rats treated with WSREt at the dose of $200 \mathrm{mg} / \mathrm{kg}$ body weight when compared to those of diabetic rats. In the present study, the activities of AST, ALT, and ALP in serum were altered in DM. In diabetic animals, the changes in the levels of AST, ALT, and ALP are directly related to changes in metabolism in which the enzymes are involved. The increased activities of transaminases, which are active in the absence of insulin due to the availability of amino acids in the blood of DM and are also responsible for the increased gluconeogenesis and ketogenesis. The restoration of AST and ALT of their respective normal level was observed in the WSREt and WSLEt treated groups. AST and ALT levels also act as an indicator of liver function, hence the restoration of normal levels of these enzymes indicates that the normal functioning of the liver. Increased activities of serum ACP and ALP have been observed in streptozotocin diabetic rats [44]. Streptozotocin-treated diabetes caused lipid peroxide-mediated tissue damage in the pancreas, liver, kidney, and heart. The increase in the levels of these enzymes in diabetes may be as a result of the leaking out from the tissues and then migrating into the bloodstream [45]. Diabetes and hyperlipidemia also cause cell damage by altering the cell membrane architecture, which results in enhanced activities of ALP in diabetic rats. In WSREt, WSLEt treated groups; the cell damage might be reverted and which may lead to the decreased activities of ALP. Therefore, the present study clearly indicates that WSREt and WSLEt possess hypoglycaemic and hypolipidaemic activities in streptozotocin-induced DM rats.

The mode of action could be either due to increased glycogenesis or decreased glycogenolysis or gluconeogenesis [46], and/or due to the insulin secretagogue effect of $W$. somnifera, which causes an increased glucose uptake and its utilization by cells [47]. The results obtained in this study are in good agreement with those observed by previous investigators in alloxan-induced diabetic rats [48-50]. According to Rerup et al.(1970) [51] Streptozotocin, beta cytotoxin induces "diabetes inducing agent" in a wide variety of animal species through a massive destruction of $\beta$-cells of the islets of Langerhans and resulting in the reduced synthesis and release of insulin. sulphonylureas produce hypoglycaemia by increasing the secretion of insulin from the pancreas and by increasing the glycogen deposition in the liver was report [52, 53], W. somnifera root contains different vital components like alanine, lysine, carbohydrates, iron, calcium, niacin and volatile oils was reported [54]. The increased insulin secretion in diabetic could be due to presence of alanine, leucine, [55] carbohydrate, niacin, iron and calcium in aqueous extract [56-58] and the various constituents in the volatile oil (indole alkaloids such as mahanine and mahanimbine, sesquiterpene such as cadinene and monoterpene such as dipentene) [59] in methanol extract of $W$. somnifera. Streptozotocin-treated animal's receiving the root extract of $W$. somnifera demonstrated rapid normalization of blood glucose levels in comparison to control and this could be due to the possibility that some ' $\beta$-cell' were still active and were acted upon by W. somnifera to extract their insulin-releasing effect and clearly indicate that the action of $W$. somnifera is probably mediated by an enhanced secretion of insulin. The increase in plasma insulin concentration could also be due to the longer lasting stimulant effect on $\beta$-cells of pancreatic islets or due to pancreatic $\beta$-cell regeneration of $W$. somnifera. In untreated diabetic (control) rats, there was a significant rise in serum triglycerides and cholesterol content. Perhaps this occurrence was because of insulin deficiency activating a lipase enzyme that hydrolyzed the stored triglycerides and mobilizing copius amounts of fatty acids and glycerol into the blood stream [60], which got eventually converted to phospholipids and cholesterol [61]. Thus, hypertriglyceridemia and hyper-cholesterolemia are the two most commonly observed lipid anomalies associated with diabetes, leading to coronary heart disease and atherosclerosis. Administration of in vitro root extracts, significantly lowered serum triglycerides and cholesterol in STZdiabetic rats groups, thus implying their ability to improve the blood lipid profile.

The present study reveals that the medicinal in vitro root extract effect of this plant was also found to be much comparable to that of the standard drug streptozotocin treated rats. It may be concluded that the methanolic in vitro root extract $W$. somnifera at the dose $(200 \mathrm{mg} / \mathrm{kg}$ ) had more potent anti-hyperglycaemic activity than the other in vitro and in vivo leaf and root extracts and was also found to be analogous effect to the standard drug 'Glibenclamide.' In conclusion, the extract of $W$. somnifera root confirms the role in the treatment of diabetes mellitus and can form a part of therapy in its management. Streptozotocin-induced diabetic rats with root 
extracts of the medicinal plant species W. somnifera resulted in a pronounced reduction of blood sugar level and normalization of biochemical (serum and urine) indices as hepatic/renal functional markers. Particularly, our finding revealed that the in vitro root has noteworthy glycemic control in diabetic rats will usher a possibility of designing and developing a potent bioactive anti-diabetic drug suitable for diabetic patients. The effectiveness of in vitro root extracts was found to be comparable to that of the standard drug glibenclamide in treated rats. Additionally, compared to natural roots in vitro roots would be a more efficient and fast-proliferating renewable resource that will ensure the round-the-year availability. Since the global scenario is now changing towards the use of plant products as alternative medicine, development of the modern drug from fast-proliferating roots of $W$. somnifera should be emphasized as an alternative and complementary medicine for the control of various diseases.

\section{CONFLICTS OF INTERESTS}

\section{Declared none}

\section{REFERENCES}

1. Sangwan RS, Chaurasiya ND, Misra LN, Lal P, Uniyal GC, Sharma $\mathrm{R}$, et al. Phytochemical variability in commercial herbal products and preparations. Curr Sci 2004;86:461-5.

2. Akhtar FM, Ali MR. Study of the antidiabetic effect of a compound medicinal plant prescription in normal and diabetic rabbits. J Pak Med Assoc 1984;34:239-44.

3. Brinker F. Herb contraindications and drug interactions. 2nd edn. USA; Eclectic Medical Publications: 1998. p. 36-82.

4. Pepato MT, Baviera AM, Vendramini RC, Perez MPMS, Ketelhut IC, Brunetti IL. Cissus sicyoides (princess vine) in the long-term treatment of streptozotocin-diabetic rats. Biotechnol Appl Biochem 2003;37:15-20.

5. Budhiraja RD, Sudhir S. Review of the biological activity of withanolides. J Sci Ind Res 1987;42:488-91.

6. Chopra RN. Glossary of Indian medicinal plants. Academic Publishers: New Delhi, India; 1994.

7. Glotter E, Kirson I, Abraham A, Lavie D. Constituents of Withania somnifera (L.) Dunal. XII. The withanolides of chemotype III. Tetrahedron 1973;29:1353-64.

8. Devi PU, Sharada AC, Solomon FE. Antitumor and radiosensitizing effects of Withania somnifera (Ashwagandha) on a transplantable mouse tumor sarcoma 180. Indian J Exp Biol 1993;31:607-11.

9. Nittala SS, Lavie S. Chemistry and genetics of withanolides in Withania somnifera hybrids. Phytochemicals 1988;20:2741-8.

10. Kandil FE, Elsayeh NH, Abou-Douh AM, Ishak MS, Mabry TJ. Flavonol glycosides and phenolics from Withania somnifera. Phytochemicals 1994;37:1215-6.

11. Bhattacharya SK, Satyam SK, Chakrabarti A. Effect of trasina an herbal ayurvedic formulation, on pancreatic islet superoxide dismutase activity in hyperglycaemic rats. Indian J Exp Biol 1997;35:297-9.

12. Tripathi AK, Shukla YN, Sushilkumar T. Ashwagandha Withania somnifera (L.) Dunal (Solanaceae): a status report. J Med Aromat Plant Sci 1996;18:46-62.

13. Andallu B, Radhika B, Dawar R. Hypoglycaemic, diuretic and hypocholesterolemic effects of winter cherry Withania somnifera (L.) Dunal root. Indian J Exp Biol 2000;6:607-9.

14. Anwer T, Sharma M, Pillai KK, Iqbal M. Effect of Withania somnifera on insulin sensitivity in non-insulin dependent diabetes mellitus rats. Basic Clin Pharmacol Toxicol 2008;102:498-503.

15. Manach C, Scalbert A, Morand C, Remesy C, Jimenez L. Polyphenols: food sources and bioavailability. Am J Clin Nutr 2004;79:727-47.

16. Sharma B, Viswanath G, Salunke R, Roy P. Effects of flavonoidrich extract from seeds of Eugenia jambolana (L.) on carbohydrate and lipid metabolism in diabetic mice. Food Chem 2008;110:697-705.

17. Murashige T, Skoog F. A revised medium for rapid growth and bioassay with tobacco tissue cultures. Physiol Plant 1962;15:473-97.
18. Stanley MP, Venugopal MP. Antioxidant action of Tinospora cordifolia root extract in alloxan diabetic rats. Phytother Res 2001;15:213-8.

19. Burits M, Bucar F. Antioxidant activity of Nigella sativa essential oil. Photother Res 2000;14:323-8.

20. Cuendet M, K Hostettmann, Potterat O, Dyatmiko W. Iridoid glucosides with free radical scavenging properties from Fagvaea blumei. Helv Chim Acta 1997;80:1144-52.

21. Yen GC, Chen HY. Antioxidant activity of various tea extracts in relation to their antimutagenicity. J Agric Food Chem 1995;43:27-32.

22. Sahu PK, Jena RC, Jena S, Panda A, Bhol R. Antidiabetic and antioxidant activity of leaf and bark extracts of Murraya koenigii on streptozotocine induced diabetic rats. Asian J Chem 2012;25:6591-6.

23. Majorie MC. Plant products as antimicrobial agents. Microbial Rev 1999;12:564-82.

24. Rasch R. Prevention of diabetic glomerulopathy in streptozotocin diabetic rats by insulin treatment: albumin excretion. Diabetologia 1980;18:413-6.

25. Diplock AT, Charleux JL, Crozier-Willi G, Kok FJ, Rice-Evans $\mathrm{C}$, Roberfroid $\mathrm{M}$, et al. Functional food science and defence against reactive oxidative species. Br J Nutr 1998;80:1:77-112.

26. Onoja SO, Anaga AO. Evaluation of the antidiabetic and antioxidant potentials of methanolic leaf extract of Helianthus annuus on alloxan-induced hyperglycemic rats. Comp Clin Pathol 2013;23:1565-73.

27. Naik GH, Priyadarsini KI, Satav GJ. Comparative antioxidant activity of individual herbal components used in ayurvedic medicine. Phytochemicals 2003;63:97-104.

28. Mosquera OM, Correa YM, Buitrago DC, Niño J. Antioxidant activity of twenty-five plants from Colombian biodiversity. Mem Inst Oswaldo Cruz 2007;102:631-4.

29. Patel DK, Prasad SK, Kumar R, Hemalatha S. An overview on antidiabetic medicinal plants having insulin mimetic property. Asian Pac J Trop Biomed 2012;2:320-30.

30. Colledge RN, Walker RB, Ralston HS. Davidson's principle and practice of medicine. Churchill Livingstone, Elsevier, Amsterdam; 2010.

31. Akhtar FM, Ali MR. Study of the anti-diabetic effect of a compound medicinal plant prescription in normal and diabetic rabbits. J Pak Med Assoc 1984;34:239-44.

32. Singh G, Sharma PK, Dudhe R, Singh S. Biological activities of Withania somnifera. Ann Biol Res 2010;1:56-63.

33. Rajangam U, Sampath K, Thankaraj SM, Manoharan $R$, Vasudevan RA, Sei CK, et al. Hypoglycaemic and hypolipidaemic effects of Withania somnifera root and leaf extracts on alloxaninduced diabetic rats. Int J Mol Sci 2009;10:2367-82.

34. Tripathi AK, Shukla YN, Sushilkumar T. Ashwagandha Withania somnifera (L.) dunal (Solanaceae): a status report. J Med Aromat Plant Sci 1996;18:46-62.

35. Andallu B, Radhika B, Dawar R. Hypoglycaemic, diuretic and hypocholesterolemic effects of winter cherry Withania somnifera (L.) Dunal root. Indian J Exp Biol 2000;6:607-9.

36. Bhattacharya SK, Satyan KS, Ghosal S. Antioxidant activity of glycol withanolides from Withania somnifera. Indian J Exp Biol 1997;35:236-9.

37. Sivajothi V, Dey A, Jayakar B, Rajkapoor B. Anti-hyperglycemic property of Tragia cannabinain streptozotocin-induced diabetic rats. J Med Food 2007;10:361-5.

38. Pathak A, Dhawan D. Effect of lithium on the levels of blood urea and creatinine in diabetic rats. Med Sci Res 1998;26:855-6.

39. Anbalagan K, Sadique J. Influence of an Indian Medicine (Ashwagandha) on acute phase reactants in inflammation. Indian J Exp Biol 1981;19:245-9.

40. Mahboob M, Rahman MF, Grover P. Serum lipid peroxidation and antioxidant enzyme levels in male and female diabetic patients. Singapore Med J 2005;46:322-4.

41. Murray RK, Granner DK, Mayes PA, Rodwell VW. Harper's Biochemistry. $25^{\text {th }}$ edn. Appleton and Lange, Stanford CT, USA; 2000.

42. Rajesh R, Chitra K, Padmaa MP. Antihyperglycemic and antihyperlipidemic activity of aerial parts of Aerva lanata Linn Juss in streptozotocin-induced diabetic rats. Asian Pasific J Trop Biomed 2012;2:924-9. 
43. Gokce G, Haznedaroglu MZ. Evaluation of antidiabetic, antioxidant and vasoprotective effects of Posidonia oceanica extract. J Ethnopharmacol 2008:115:122-30.

44. Prince PSM, Menon VP, Pari L. Effect of Syzigium cumin extracts on hepatic hexokinase and glucose-6-phosphatase in experimental diabetes. Phytother Res 1997;11:529-31.

45. Prince PSM, Menon VP. Hypoglycaemic and other related actions of Tinospora cardifolia roots in alloxan-induced diabetic rats. J Ethnopharmacol 2000;70:9-15.

46. Khan BA, Abraham A, Leelamma S. Anit-oxidant effects of curry leaf, Murraya koenigii and mustard seeds, Brassica juncea in rats fed with high-fat diet. Indian J Exp Biol 1997;35:148-50.

47. Radhika S, Senthilkumar R, Arumugam P. A review on ethnic florae with antihyperglycemic efficacy. Int J Herb Med 2013;1:55-62.

48. Vinuthan MK, Girish KV, Ravindra JP, Narayan JK. Effect of extracts of Murraya koenigii leaves on the levels of blood glucose and plasma insulin in alloxan-induced diabetic rats. Indian J Physiol Pharmacol 2004;48:348-52.

49. Chude MA, OJ Orisakwe, KS Gamaniel, OH Vongtau, E Obi. Hypoglycaemic effect of the aqueous extract of Boerhavia diffusa leaves. Ind J Pharmacol 2001;33:215-6.

50. Pari L, Amarnath SM. Antidiabetic activity of Boerhaavia diffusa L.: effect on hepatic key enzymes in experimental diabetes. J Ethnopharmacol 2004;91:109-13.

51. Rerup CC. Drugs producing diabetes through damage of the insulin secreting cells. Pharmacol Rev 1970;22:485-518.

52. Grodsky GM, Epstein GH, Fanska R, Karam JH. The pancratic action of the sulfonylureas. Fed Proc 1977;36:2714-9.

53. Yallow RS, Black H, Villazan M, Berson SA. Comparison of plasma insulin levels following administration of tolbutamide and glucose. Diabetes J 1960;9:356-62.
54. Kandil FE, Elsayeh NH, Abou-Douh AM, Ishak MS, Mabry TJ Flavonol glycosides and phenolics from Withania somnifera. Phytochemicals 1994:37:1215-6.

55. Pruthi JS. Spices, Condiment. National Book Trust, Green Park, JK. Offset Printers, 315, Jama Masjid, New Delhi; 1979. p. 108-11.

56. Berne RM. Levy MN. Control of cardiac output: Coupling of heart and blood vessels. In: Berne RM, Levy MN. Eds. Physiology. Mosby. Co: St. Louis: 1988. p. 525-39.

57. Murray RK, Granner DK, Mayes A, Rodwell VW. Harper's biochemistry. 24th edn. Prentice-Hall International: USA; 1996

58. Satyanarayana U. In: A Sen. Biotechnology, Metabolism in Biochemistry, Books, and Allied (P) Ltd. 1st edn. Chintamoni Das Lane; Calcutta; 1999. p. 247-449.

59. Rasch R, Mogensen CE. Urinary excretion of albumin and total protein in normal and streptozotocin diabetic rats. Acta Endocrinol 1980;95:376-81.

60. Shirwaikar A, Rajendra K, Barik R. Effect of aqueous bark extract of Garuga pinnata Roxb. In streptozotocin-nicotinamide induced type-II diabetes mellitus. J Ethnopharmacol 2006;107:285-90.

61. Al-Logmani AS, Zari TA. Effects of Nigella sativa L. and Cinnamomum zeylanicum Blume oils on some physiological parameters in streptozotocin-induced diabetic rats. Bol Latinoam Caribe Plant Med Aromat 2009;8:86-96

\section{How to cite this article}

- Somanatha Jena, Ram C Jena, Rasmita Bhol, Khusbu Agarwal, Ansuman Sarangi, Pramod K Sahu, Swarna L Mishra. A comparative study of the anti-oxidative and anti-diabetic potential of in vitro and in vivo root and leaf extracts of Withania somnifera on streptozotocin induced diabetic rats. Int J Pharm Pharm Sci 2016;8(10):85-91 